Supporting Information for:

\title{
P-Type Electrochemical Doping Can Occur by Cation Expulsion in a High Performing Polymer for Organic Electrochemical Transistors
}

Lucas Q. Flagg†, Connor G. Bischak†, Ramsess J. Quezada $\uparrow$, Jonathan W. Onorato $\ddagger$, Christine. K. Luscombet+ + , David S. Ginger $\dagger^{*}$

$\uparrow$ Department of Chemistry, University of Washington, Seattle, Washington 98195-1700, United States

†Department of Materials Science and Engineering, University of Washington, Seattle, Washington 98195-2120, United States

+Department of Molecular Engineering, University of Washington, Seattle, Washington, 981951652, United States

*Address correspondence to ginger@chem.washington.edu

Methods

Figure S1: EQCM calibration

Figure S2: Repeated EQCM scans

Figure S3: Spectroelectrochemistry measurements

Figure S4: EQCM on additional chloride salts

Figure S5: Optical images of doped films

Figure S6: Absorption spectrum of rinsed film

Figure S7: Normalization procedure for GDOES data

Figure S8: Calibration of GDOES signal strength

Figure S9: Raw GDOES spectra

Figure S10: GDOES in other salts

Figure S11: Zero bias absorption spectra

Figure S12: GDOES with injected charge overlaid

Figure S13: Change in film stiffness during doping

Figure S14: Apparent molar mass of dopant species

Figure S15: Schematic of doping in $\mathrm{KCl}$

References for supporting information 


\section{Methods:}

Materials: All salts $\left(\mathrm{KCl}, \mathrm{NaCl}, \mathrm{CsCl}, \mathrm{TBACl}, \mathrm{KPF}_{6}, \mathrm{TBAPF}_{6}\right)$ were purchased from Sigma Aldrich and dried in a vacuum oven before use. Chlorobenzene was also purchased from Sigma Aldrich and used as received. N-bromosuccinimide was recrystallized from water prior to use. Tetrahydrofuran (THF) and dichloromethane (DCM) were dried and deoxygenated on a PureSolv solvent purification system. All other reagents were used as received from Sigma Aldrich.

\section{Polymer Synthesis and Characterization:}

All reactions were performed under nitrogen using standard Schlenk line techniques, and all glassware was dried overnight at $120^{\circ} \mathrm{C}$ prior to use. 2,5-dibromo-3methoxyethoxyethoxymethylthiophene was synthesized using a modified literature procedure. ${ }^{1}$ NMR was performed using either a $300 \mathrm{MHz}$ Bruker AV-300 or a $500 \mathrm{MHz}$ Bruker AV-500 at $25^{\circ} \mathrm{C}$. The synthesized polymer's molecular weight was characterized using size exclusion chromatography (SEC), on a Malvern Viscotek TDA 305 GPC coupled to a UV-detector. Samples were run at $30^{\circ} \mathrm{C}$ using $\mathrm{CHCl}_{3}$ at a flow rate of $1 \mathrm{~mL} / \mathrm{min}$ as an eluent.

\section{Monomer Synthesis:}

3-thiophenemethanol $(3.77 \mathrm{~mL}, 40 \mathrm{mmol})$ and $36.4 \mathrm{~mL}$ of THF were added to a 3-neck flask, and then degassed by nitrogen bubbling for 15 minutes. Then, recrystallized NBS (total: $14.15 \mathrm{~g}$, $79.5 \mathrm{mmol}$ ) was added to the reaction quickly, across 5 equivalent portions, recapping the reaction in between each addition. The reaction was stirred overnight, then filtered, and the solvent removed using rotary evaporation. The residue was purified using column chromatography with a hexanes to ethyl acetate mixture of $4: 1$. The product was collected as a white solid in 90\% yield. ${ }^{1} \mathrm{H}$ NMR $\left(300 \mathrm{MHz}, \mathrm{CDCl}_{3}\right): \delta 7.03(\mathrm{~s}, 1 \mathrm{H}), 4.60(\mathrm{~s}, 2 \mathrm{H})$, and $1.95(\mathrm{br}$, $1 \mathrm{H})$.

2,5-dibromo-3-thiophenemethanol $(9.0 \mathrm{~g}, 33.5 \mathrm{mmol})$ and $165 \mathrm{~mL}$ of DCM were added to a round bottom flask, then cooled over ice for 20 minutes. $\mathrm{PBr}_{3}(3.20 \mathrm{~mL}, 34.25 \mathrm{mmol})$ was added dropwise over the course of 15 minutes, then the reaction was allowed to warm to room temperature. The reaction was stirred for 5 hours at room temperature, then quenched with 100 $\mathrm{mL}$ of $10 \% \mathrm{NaHCO}_{3}$ solution. Allow bubbling to subside, then extract the product with DCM, wash with brine, and dry over $\mathrm{MgSO}_{4}$. The solvent was removed through rotary evaporation, and the product was placed in the freezer overnight at $-20{ }^{\circ} \mathrm{C}$, after which it was recovered as a white solid in 93\% yield. ${ }^{1} \mathrm{H}$ NMR $\left(300 \mathrm{MHz}, \mathrm{CDCl}_{3}\right): \delta 7.00(\mathrm{~s}, 1 \mathrm{H}), 4.36(\mathrm{~s}, 2 \mathrm{H})$.

To a 3-neck flask equipped with an addition funnel, diethylene glycol monomethyl ether (3.5 $\mathrm{mL}, 30 \mathrm{mmol})$ and $100 \mathrm{~mL}$ of THF were added. To this, NaH (1.32 g, $33 \mathrm{mmol})$ was added in on portion, and allowed to react for 10 minutes. During this time, 2,5-dibromo-3thiophenemethylbromide ( $9.65 \mathrm{~g}, 29 \mathrm{mmol}$ ) was dissolved in $25 \mathrm{~mL}$ of THF, and added to the addition funnel. It was then added dropwise over the course of 15 minutes, and the reaction was stirred overnight at room temperature, resulting in the formation of a significant amount of salt precipitate. The reaction mixture was filtered over a thin pad of Celite to remove salt, and the product was washed through with excess THF. The THF was removed through rotary evaporation, and the product was purified using a column run with a 3:2 mixture of hexanes:ethyl acetate. The recovered product was a pale yellow oil and was collected in $87 \%$ 
yield, and was stored at $-20{ }^{\circ} \mathrm{C}$ and away from light. ${ }^{1} \mathrm{H}$ NMR $\left(300 \mathrm{MHz}, \mathrm{CDCl}_{3}\right) \delta 7.0(\mathrm{~s}, 1 \mathrm{H})$, $4.43(\mathrm{~s}, 2 \mathrm{H}), 3.65(\mathrm{~m}, 6 \mathrm{H}), 3.57(\mathrm{~m}, 2 \mathrm{H}), 3.39(\mathrm{~s}, 3 \mathrm{H})$.

Polymer Synthesis:

2,5-dibromo-3-methoxyethoxyethoxymethylthiophene (372 $\mathrm{mg}, 1 \mathrm{mmol}$ ) was added to a Schlenk flask, then degassed under high vacuum for 30 minutes. Then $10 \mathrm{~mL}$ of THF was added, and the mixture was cooled to $0{ }^{\circ} \mathrm{C}$, and $i-\mathrm{PrMgCl}(2.0 \mathrm{M}$ in THF, $0.5 \mathrm{~mL}, 1.0 \mathrm{mmol})$ was added dropwise over 10 minutes, stirring vigorously. The flask was allowed to warm to room temperature and stirred for 1 hour. To begin the polymerization, the flask was heated to $45{ }^{\circ} \mathrm{C}$, and then $\mathrm{Ni}(\mathrm{dppp}) \mathrm{Cl}_{2}(4.334 \mathrm{mg}, 0.008 \mathrm{mmol})$ was added rapidly in one portion, after which the polymerization was left to stir vigorously at $45{ }^{\circ} \mathrm{C}$ for 2 hours. The polymerization was quenched with the addition of $\mathrm{HCl}(5 \mathrm{M}, 1.0 \mathrm{~mL})$, and the polymer was precipitated into $400 \mathrm{~mL}$ of $\mathrm{MeOH}$. The resultant precipitate was allowed to settle briefly, then collected over a filter. The collected solid was then purified using successive Soxhlet extractions with hexanes and $\mathrm{MeOH}$, and then collected using chloroform. The chloroform was removed, and the polymer was redissolved into THF, then precipitated into $\mathrm{MeOH}$ and collected over a filter. ${ }^{1} \mathrm{H}$ NMR (500 $\left.\mathrm{MHz}_{2} \mathrm{CDCl}_{3}\right) \delta 7.25(\mathrm{~s}, 1 \mathrm{H}), 4.67(\mathrm{~s}, 2 \mathrm{H}), 3.75(\mathrm{~s}, 4 \mathrm{H}), 3.67(\mathrm{~m}, 2 \mathrm{H}), 3.57(\mathrm{~m}, 2 \mathrm{H}), 3.37(\mathrm{~s}, 3 \mathrm{H})$. $Ð=2.0, M_{n}=11 \mathrm{~kg} / \mathrm{mol}$.

\section{Sample Preparation:}

The polymer was dissolved in chlorobenzene at $20 \mathrm{mg} / \mathrm{mL}$ concentration and stirred at $800 \mathrm{rpm}$ overnight at room temperature. Films were created by depositing $60 \mu \mathrm{L}$ of solution onto QCM crystals or ITO substrates (for GDOES) and spinning for 60 seconds at $1000 \mathrm{rpm}$ (thickness $\sim 80$ $\mathrm{nm}$ ). All electrolytes were made at $20 \mathrm{mM}$ concentration in Milli-Q water by stirring overnight at room temperature.

\section{Electrochemical Quartz Crystal Microbalance (EQCM) Gravimetry:}

Electrogravimetric measurements were made using 1 in. diameter gold-coated AT quartz crystals (Stanford Research Systems) on an SRS QCM200 instrument. The electrochemical potential was applied in a 3-electrode cell with the polymer coated QCM crystal serving as the working electrode, a platinum mesh serving as the counter electrode (Aldrich), and an $\mathrm{Ag} / \mathrm{AgCl}$ puck electrode (A-M Systems, Inc.) serving as the reference electrode. A potentiostat (MetroOhm Autolab PGSTAT204) was used to apply the bias, record the current, and simultaneously record the oscillator frequency and series resonance resistance from the EQCM. The apparent molar mass of the dopant species is calculated from the slope of a change in mass versus injected charge plot as described by Zhang et al. ${ }^{2}$ Previous EQCM studies have shown that thin $(\sim 100 \mathrm{~nm})$ conducting polymer films on the quartz crystals do not cause a significant deviation from the rigid film approximation; therefore, it can be assumed that the frequency shifts measured here are a direct measure of mass changes in the polymer layer. ${ }^{3-5}$

\section{Glow Discharge Optical Emission Spectroscopy (GDOES):}

We prepared samples for GDOES at the desired doping level by using polymer coated ITO substrates as the working electrode in the same 3-electrode cell as mentioned above. During a 
cyclic voltammetry scan, we removed the polymer film from solution at the desired oxidation state. Once removed from solution, we used a nitrogen gun to blow off as much remailing electrolyte as possible and then rinsed the sample in 3 successive DI water baths. We then used a GD profiler 2 from Horriba Scientific with the RF plasma settings shown in Table S1 to analyze the elemental content within the film. Using these settings, we completely etched through the polymer in 5-25 seconds.

Due to variation in the plasma etching, it is hard to directly compare elemental content between samples. To allow comparisons, we develop the following normalization procedure. First, we extract a baseline signal intensity for each element by averaging the signal over the final 30 seconds of etch when all polymer signal is gone. We then subtract this baseline from the raw signal. Next, we integrate the signal in time to get a total signal value. Since the only sulfur present in the samples is from the polymer backbone, the total sulfur signal should be constant for all samples. Therefore, by dividing the integrated ion signals (potassium and phosphorous) by the integrated sulfur signal we can correct for variations in etch rate and make comparisons of ion content between multiple samples.

Table S1: RF plasma settings

\begin{tabular}{|l|l|}
\hline Pressure & $400 \mathrm{~Pa}$ \\
\hline Power & $15 \mathrm{~W}$ \\
\hline Frequency & $1000 \mathrm{~Hz}$ \\
\hline Duty Cycle & 0.0625 \\
\hline Resulting Power & $0.9375 \mathrm{~W}$ \\
\hline Module & $7 \mathrm{~V}$ \\
\hline Phase & $4 \mathrm{~V}$ \\
\hline
\end{tabular}




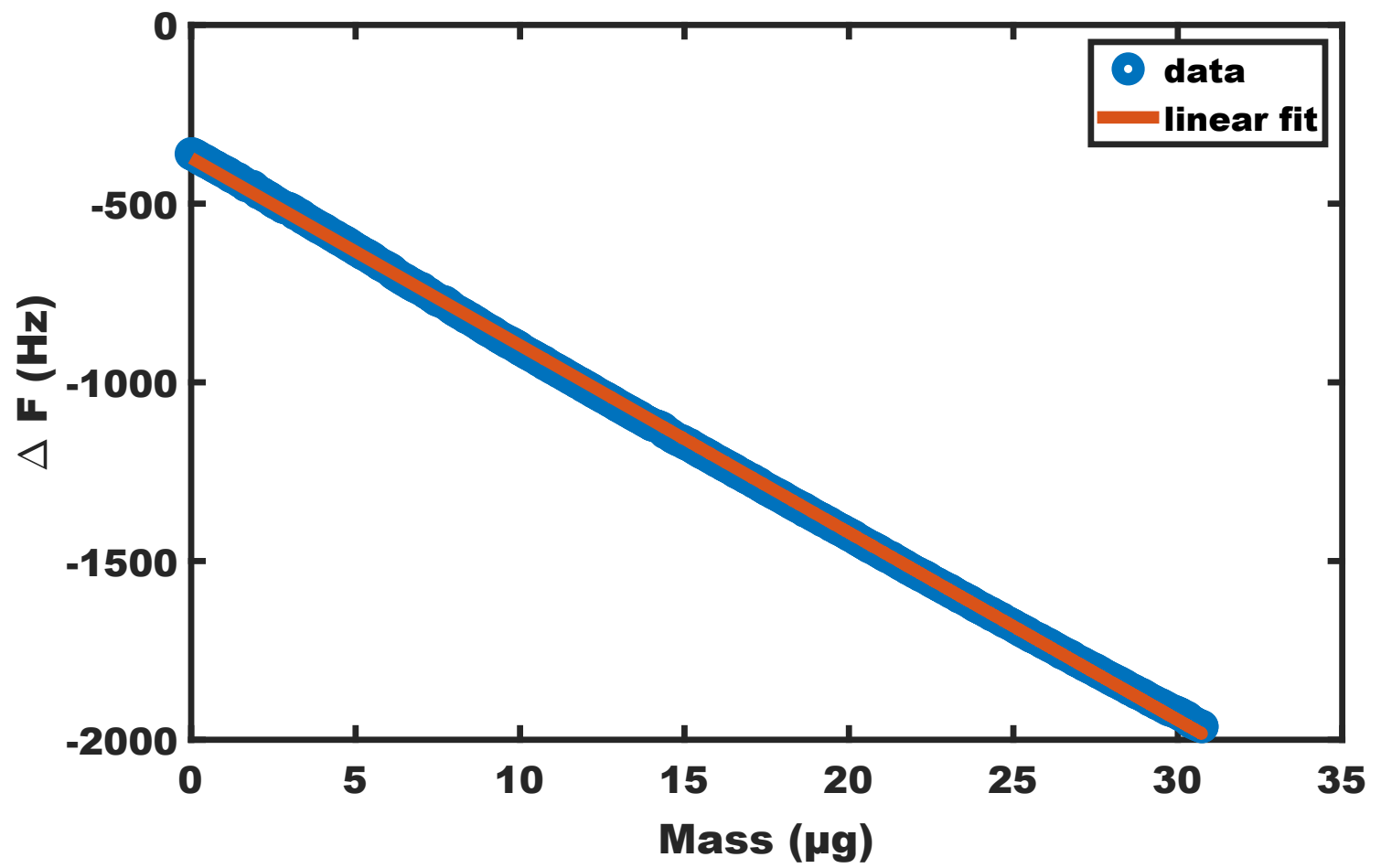

Figure S1: EQCM calibration. We use the electrodeposition of $\mathrm{Ag}\left(50 \mathrm{mM} \mathrm{AgNO}_{3}\right.$ in $0.5 \mathrm{M}$ $\left.\mathrm{HNO}_{3}\right)$ at a constant current of $40 \mu \mathrm{A}$ to calibrate the sensitivity factor $\left(\mathrm{C}_{\mathrm{f}}\right)$ and active area of the EQCM as described in the literature. ${ }^{6}$ 

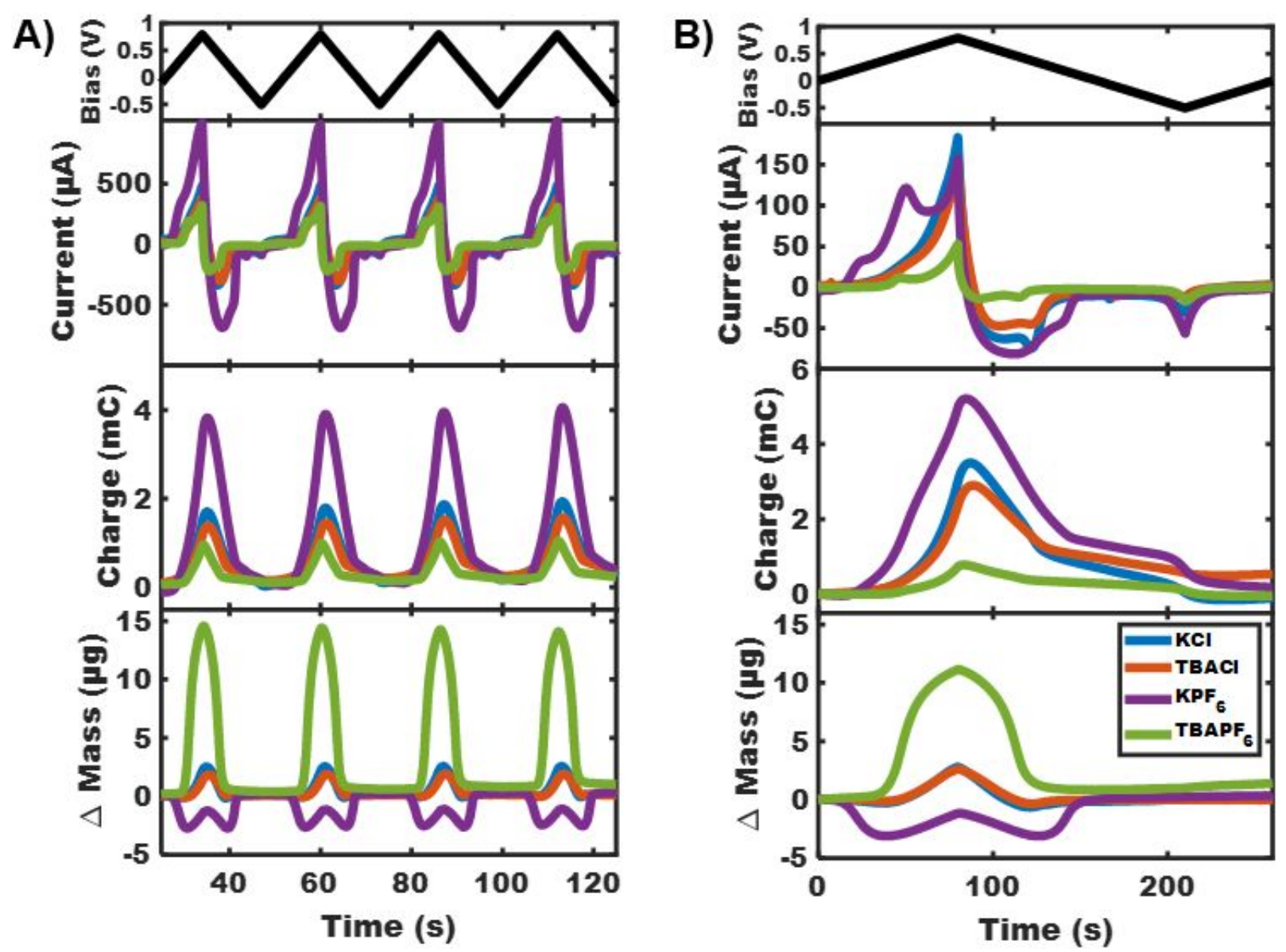

Figure S2: Repeated scans at different bias sweep rates in 4 different electrolytes. A) Shows the bias, current, charge, and change in mass as a function of time over 4 cycles at a bias sweep rate of $100 \mathrm{mV} / \mathrm{s}$. The oxidation/reduction cycle is reversible in all electrolytes shown. B) Shows the bias, current, charge, and change in mass in 4 different salts data during a $10 \mathrm{mV} / \mathrm{s}$ scan. 
A)

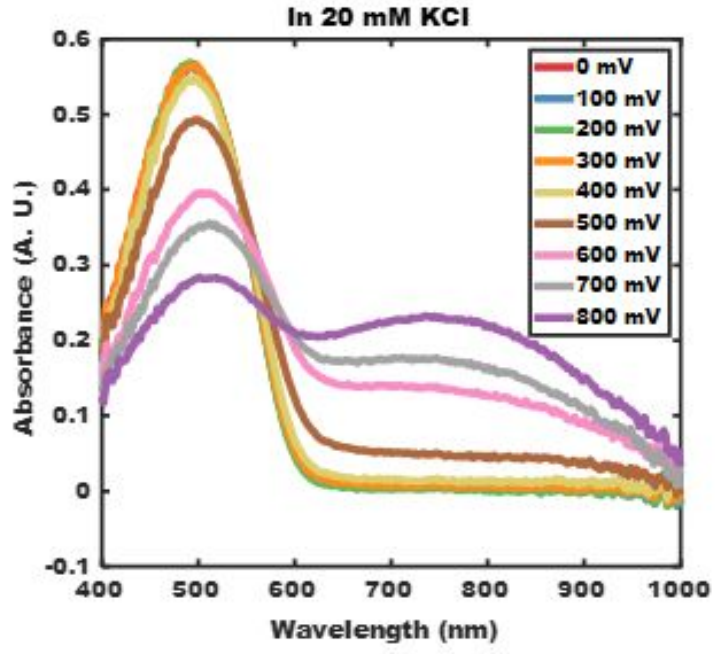

C)

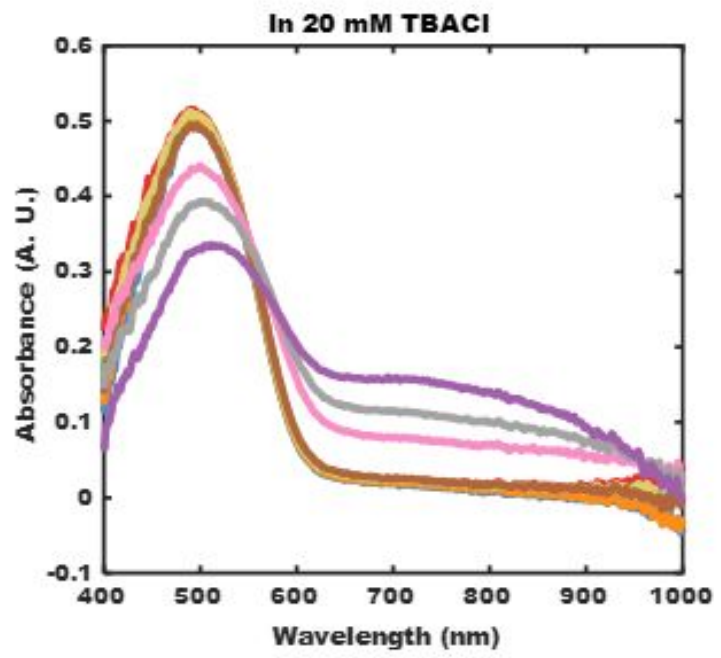

B)

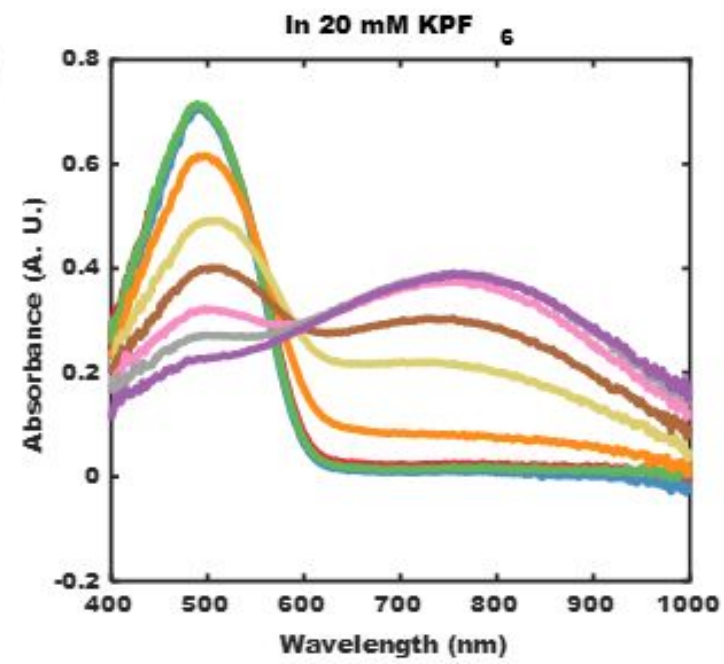

D)

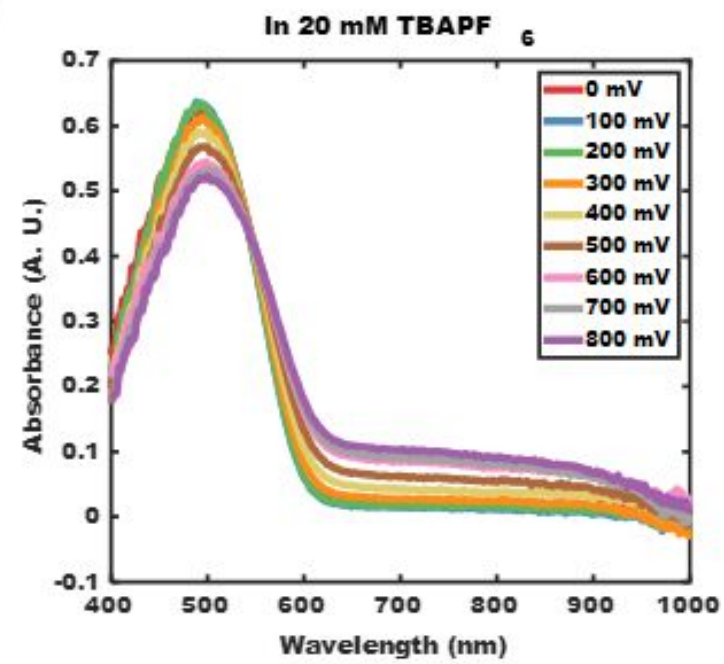

Figure S3: Spectroelectrochemistry in A) $20 \mathrm{mM} \mathrm{KCl,} \mathrm{B)} 20 \mathrm{mM} \mathrm{KPF}_{6}$, C) $20 \mathrm{mM} \mathrm{TBACl}$, and D) $20 \mathrm{mM} \mathrm{TBAPF}_{6}$. These data confirm an electrolyte dependent shift in both the magnitude of doping and the onset of oxidation. 

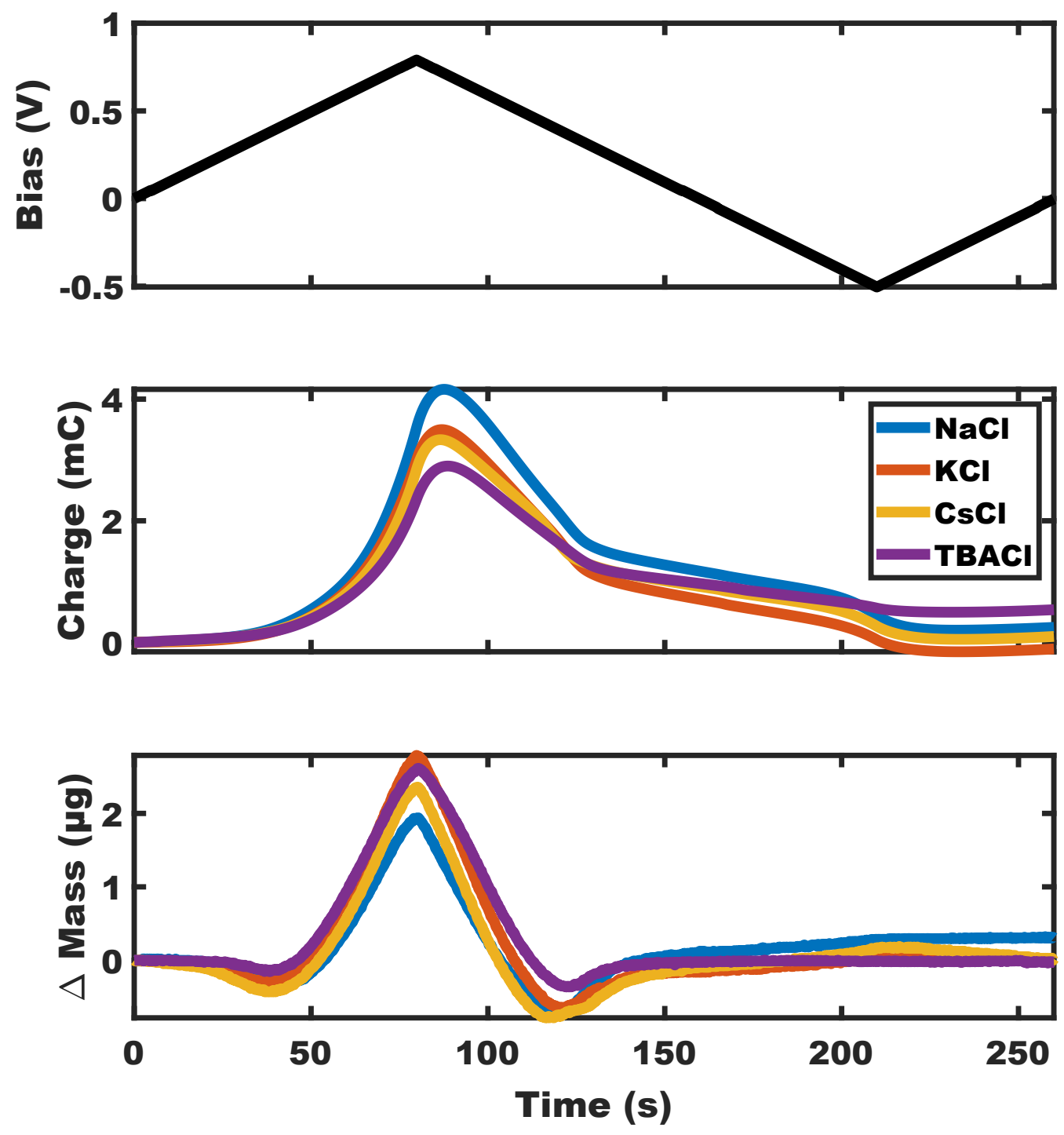

Figure S4: EQCM data including two additional chloride salts $(\mathrm{NaCl}$ and $\mathrm{CsCl})$ showing qualitative agreement between all 4 chloride salts tested. 


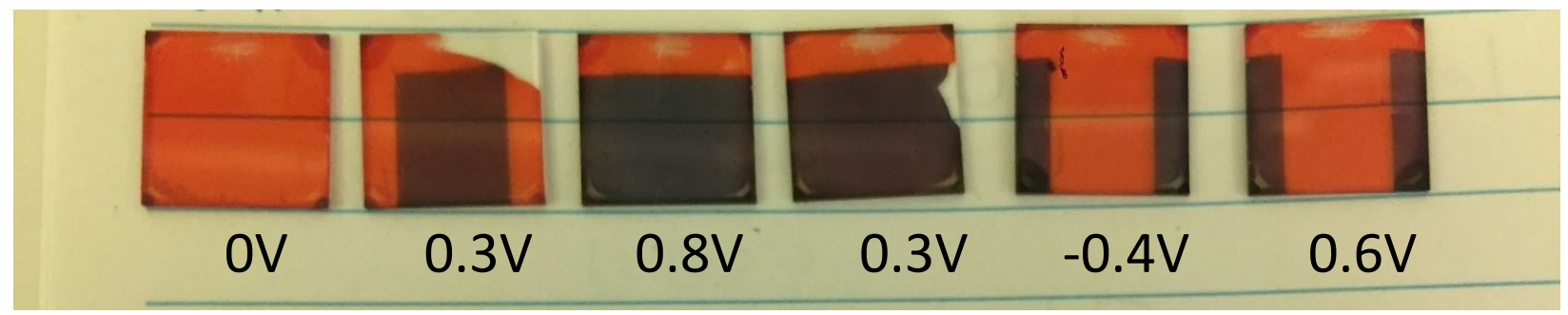

Figure S5: Optical images of a series of polymer films on patterned ITO substrates removed from the electrolyte at different stages of oxidation and rinsed. There is a thin film ITO strip down the center of the glass samples leading to the different doping on the edges of the samples.

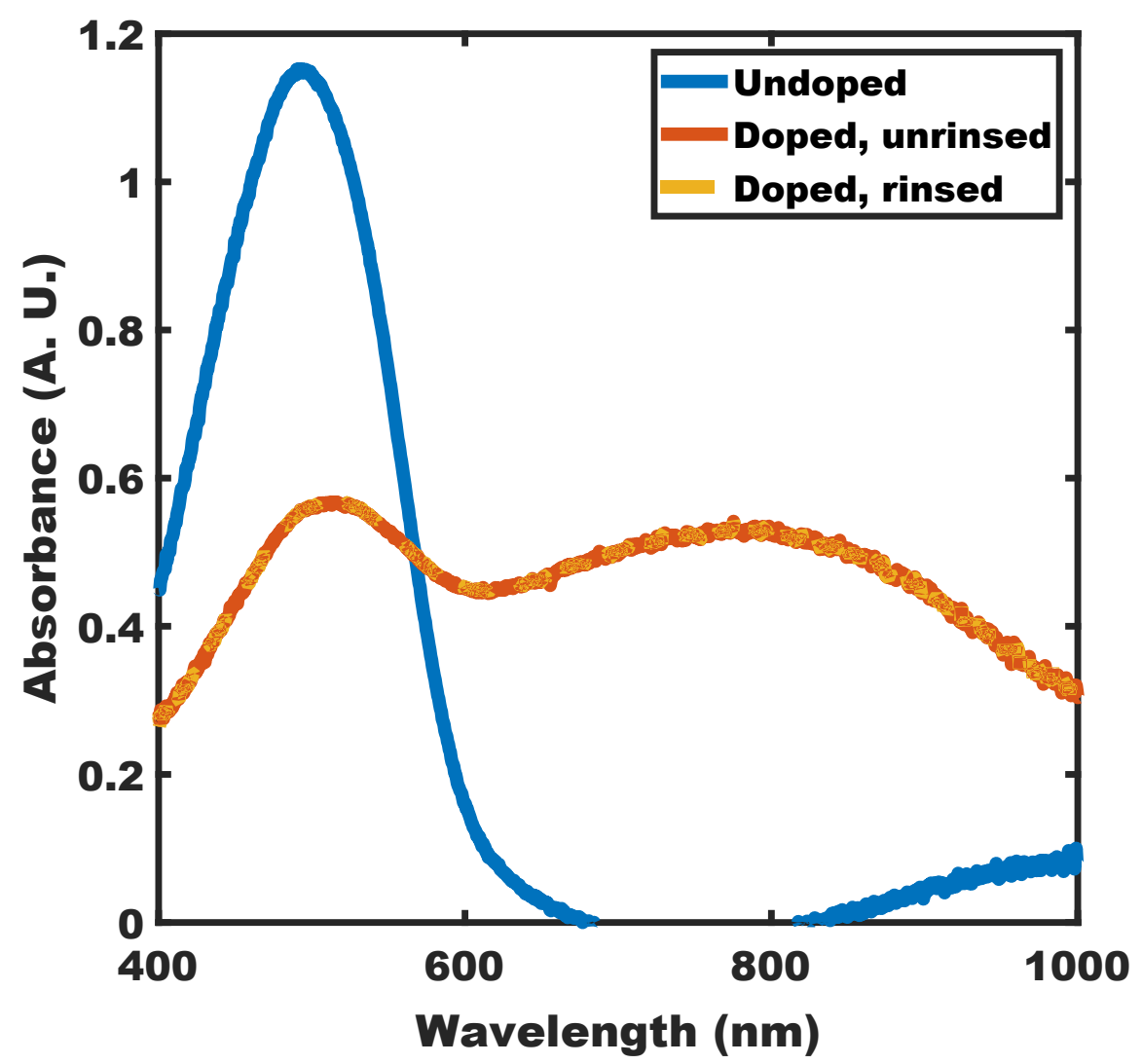

Figure S6: UVVis absorption of a dry, undoped polymer film (blue), a doped polymer film after drying in an $\mathrm{N}_{2}$ stream (orange), and a doped polymer film after rinsing 3 times in DI water (yellow). These data confirm that the rinse step does not cause significant dedoping of the film. 

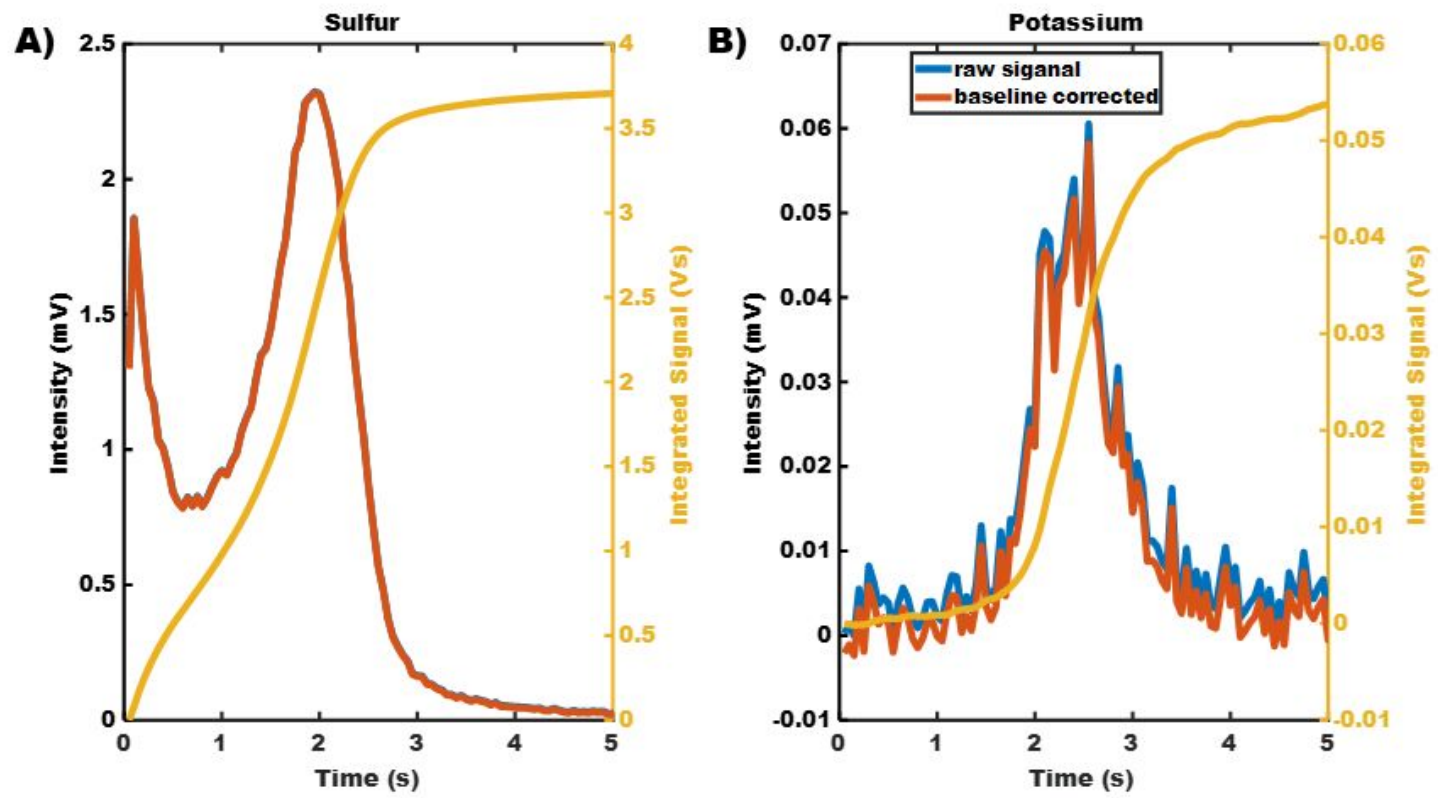

Figure S7: Illustration of the normalization procedure used. A) Shows an example of the raw sulfur signal (blue) and the baseline corrected signal in orange on the left axis. The right axis shows the total integrated signal (yellow). B) Shows an example of the raw potassium signal (blue), the baseline corrected signal (orange), and the total integrated signal on the right axis (yellow). 


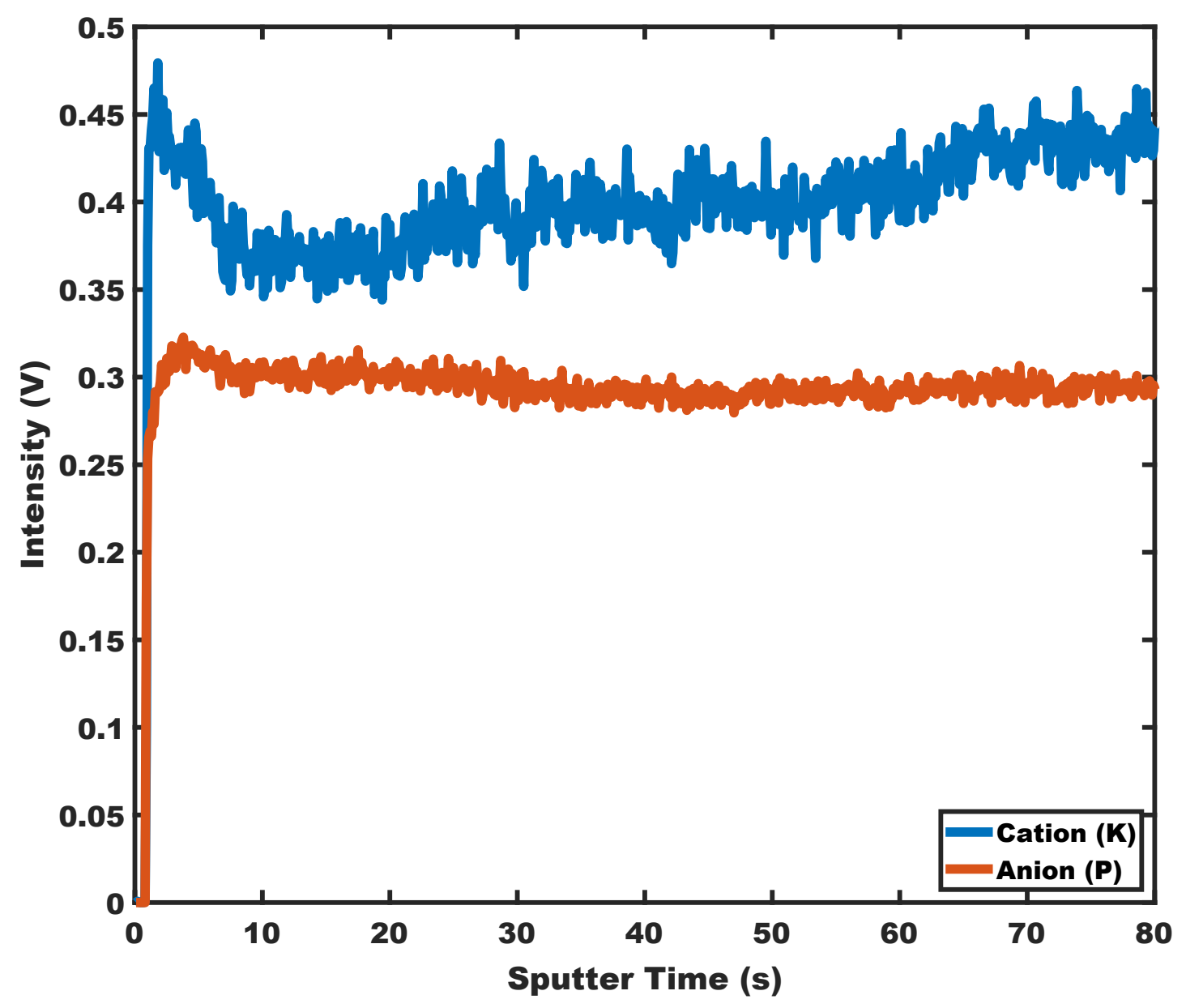

Figure S8: Calibration of the GDOES signal. We dry $100 \mathrm{mM} \mathrm{KPF}_{6}$ salt on a glass substrate which presumably results in a 1:1 ratio of potassium to phosphorus. The data shows that the potassium signal is stronger than the phosphorus signal when there are equal amounts of each element. This difference in instrumental sensitivity to the potassium and phosphorus signals indicates that only relative changes are meaningful. 

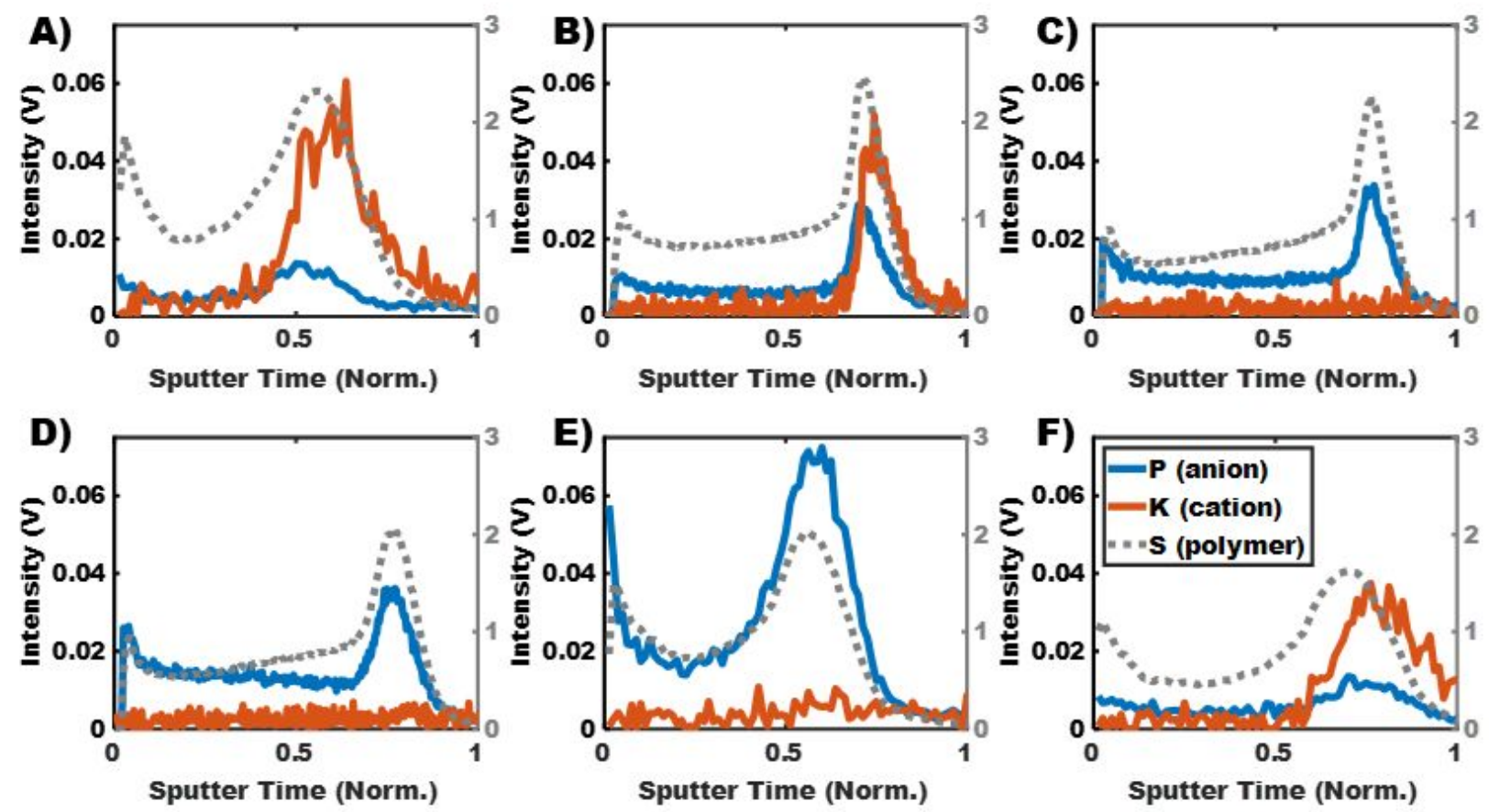

Figure S9: Raw GDOES Spectra at 6 different oxidation states. For all spectra the phosphorus (anion) signal is plotted in blue and the potassium signal (cation) is plotted in orange against the left axis. On the right axis is gray is the sulfur content provided as a reference for the variation in etch rate. A) shows the GDOES spectra at $0 \mathrm{~V}$ after the sample is submerged in $\mathrm{KPF}_{6}$ for 30 seconds. B) shows the GDOES spectra of a sample doped at $300 \mathrm{mV}$. C) shows the GDOES spectra of a sample doped t $400 \mathrm{mV}$. D) shows the GDOES spectra of a sample doped at $500 \mathrm{mV}$. E) shows the GDOES spectra of a sample doped at $700 \mathrm{mV}$. F) shows the GDEOS spectra at $0 \mathrm{~V}$ after completing one full bias cycle. 


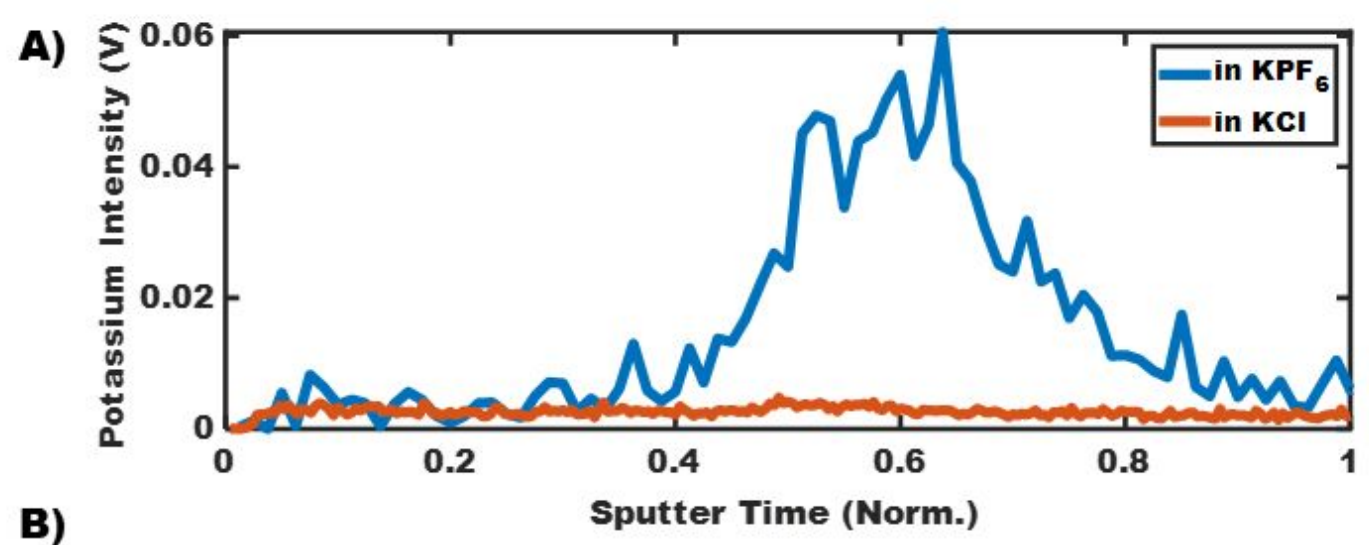

B)

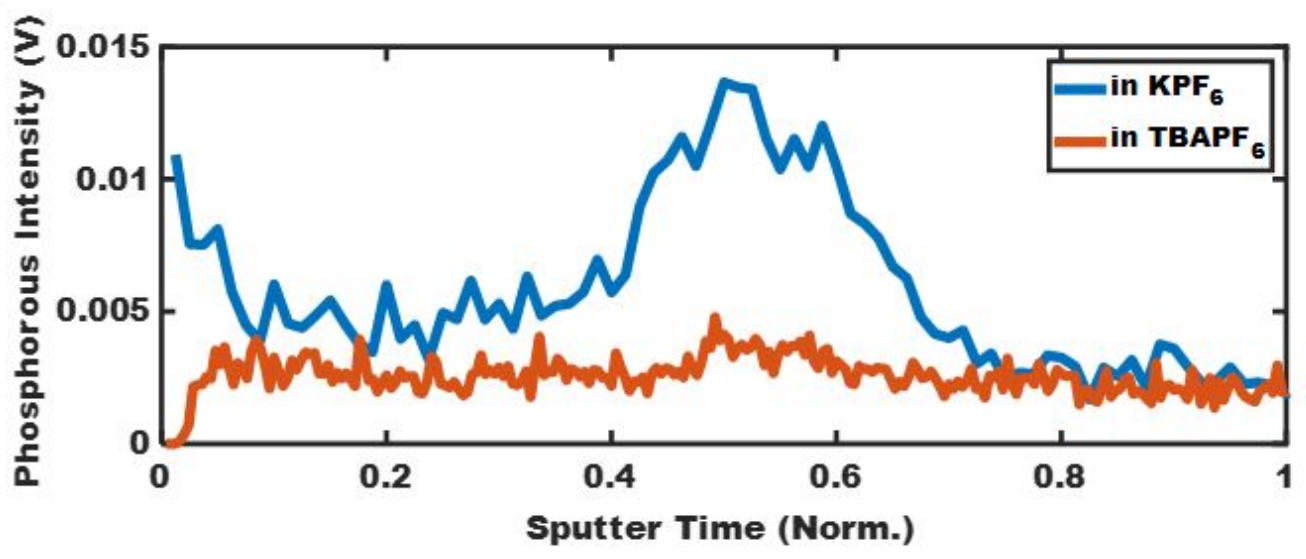

Figure S10: GDOES in other salts. A) Shows the potassium signal of a film dipped in $\mathrm{KPF}_{6}$ (blue) and in $\mathrm{KCl}$ (orange). The orange trace shows that when chloride is the anion we do not detect any cation in the film. B) Shows the phosphorous signal of a film dipped in $\mathrm{KPF}_{6}$ (blue) and $\mathrm{TBAPF}_{6}$ (orange). The orange trace shows that when TBA is the cation, we do not detect any anion within the film. 


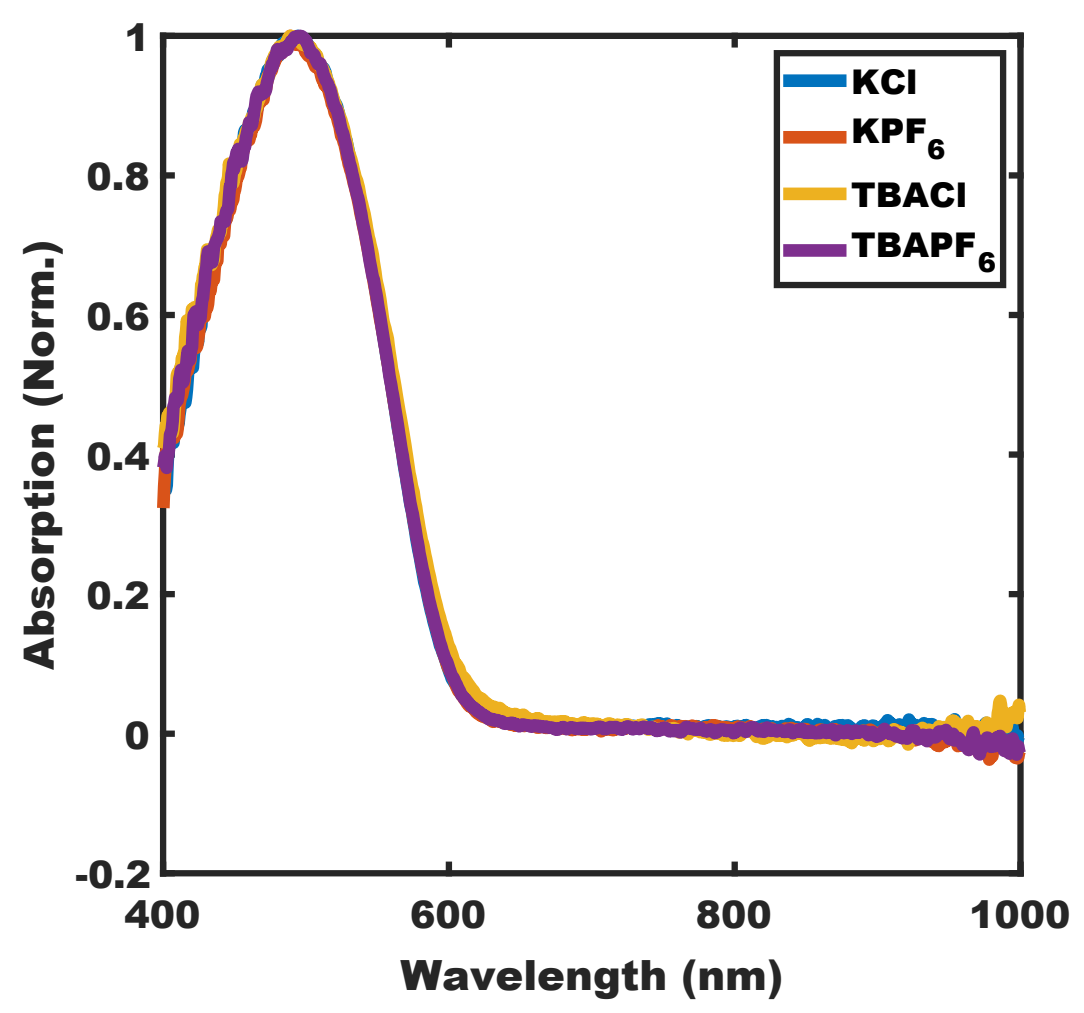

Figure S11: Zero bias absorption spectrum in each of the electrolytes. The lack of absorption in the $800 \mathrm{~nm}$ region indicates that there is no "passive doping" in any of the electrolytes used. 


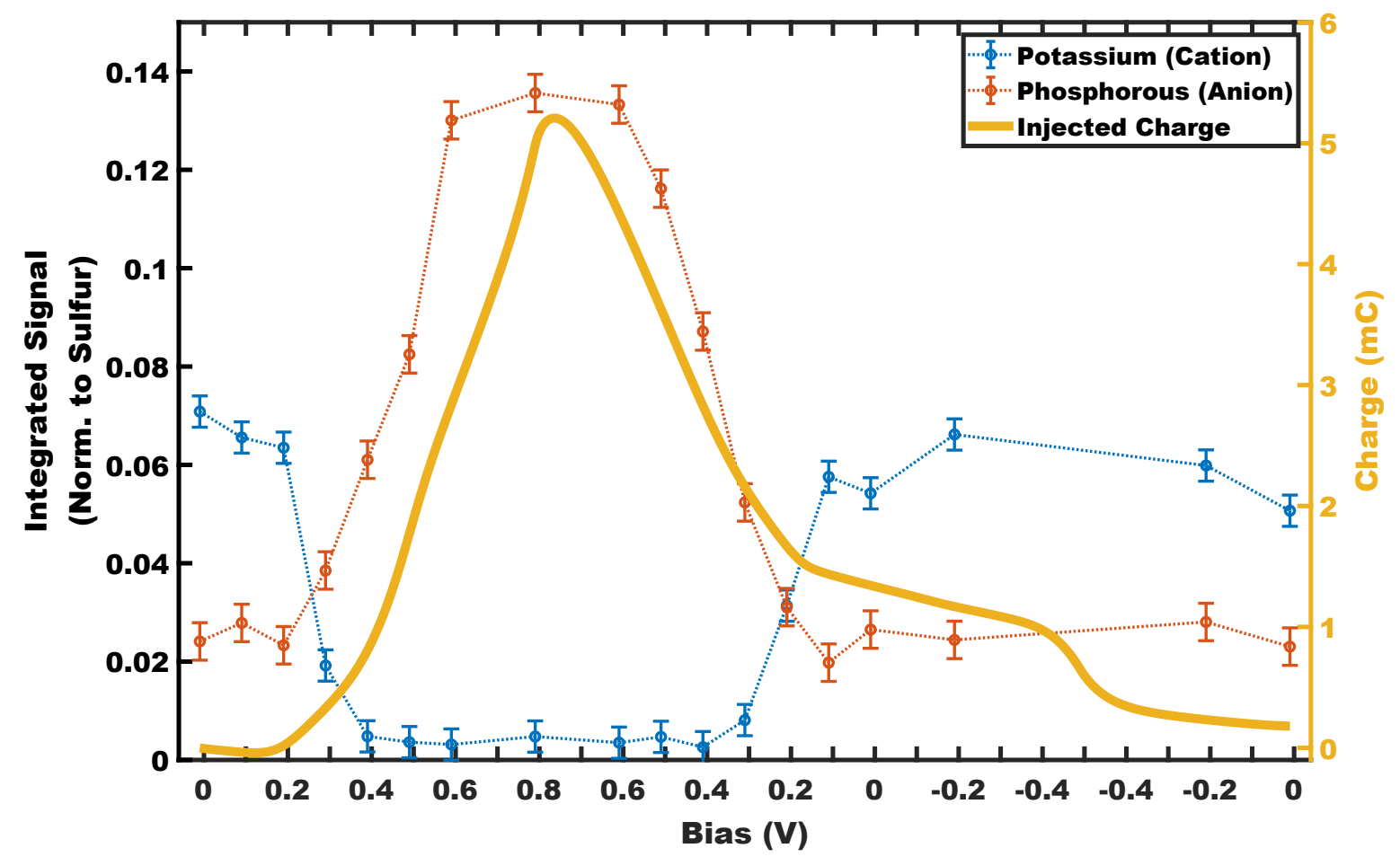

Figure S12: Glow Discharge Optical Emission Spectroscopy (GDOES). The left axis shows the cation (blue) and anion (orange) content as a function of applied bias. The right axis overlays the injected charge (yellow). 


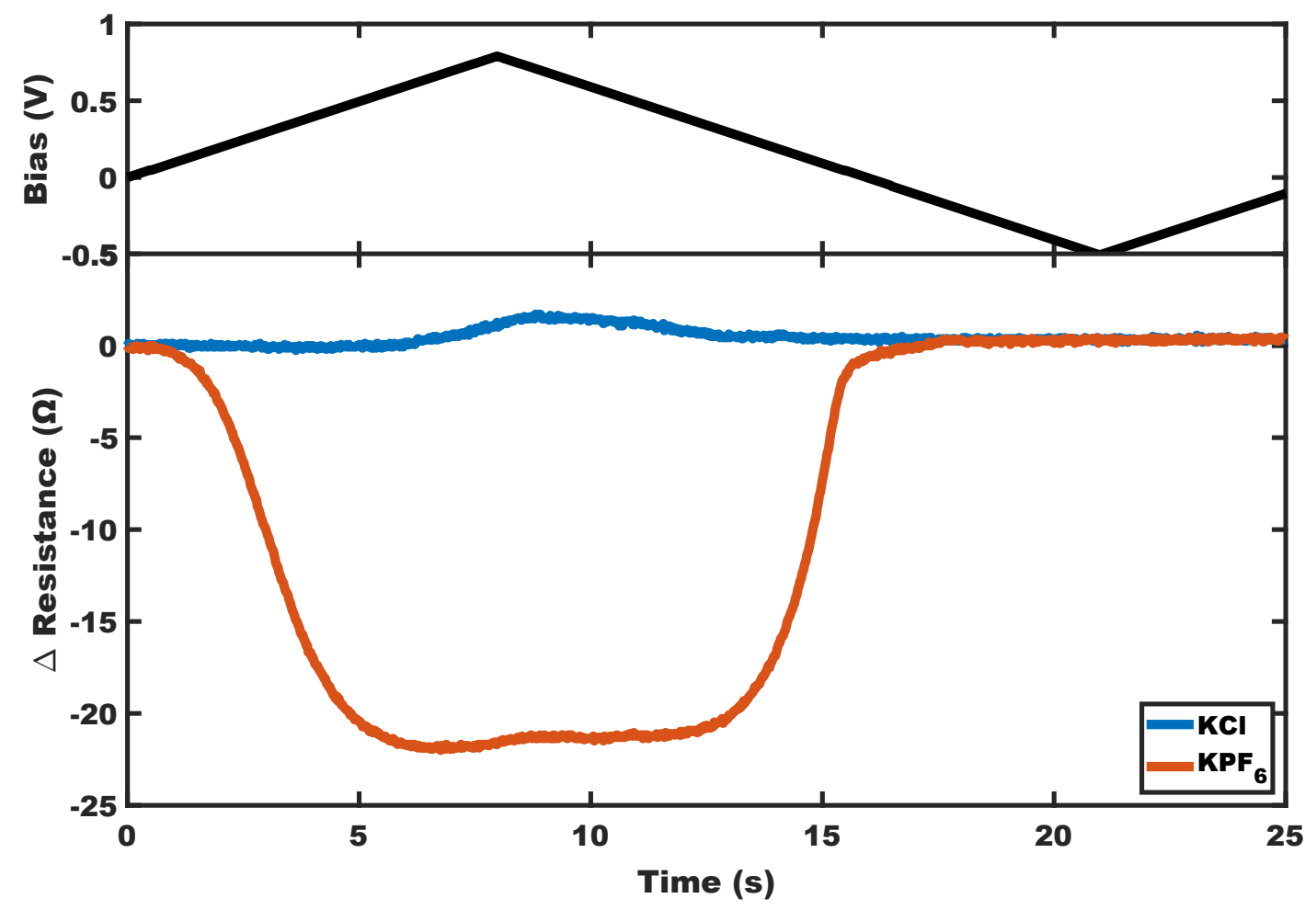

Figure S13: Change in film stiffness. Here we plot the series resonance resistance of the quartz oscillator during a cyclic voltammetry scan in $\mathrm{KCl}$ (blue) and in $\mathrm{KPF}_{6}$ (orange). An increase in the resistance corresponds to a softer film and a decrease indicates the film is getting stiffer. When doped in $\mathrm{KCl}$ the film gets softer by $2 \Omega$, likely due to the inclusion of water. ${ }^{7}$ When the film is oxidized in $\mathrm{KPF}_{6}$, the film gets stiffer by $22 \Omega$, suggesting the expulsion of water. 

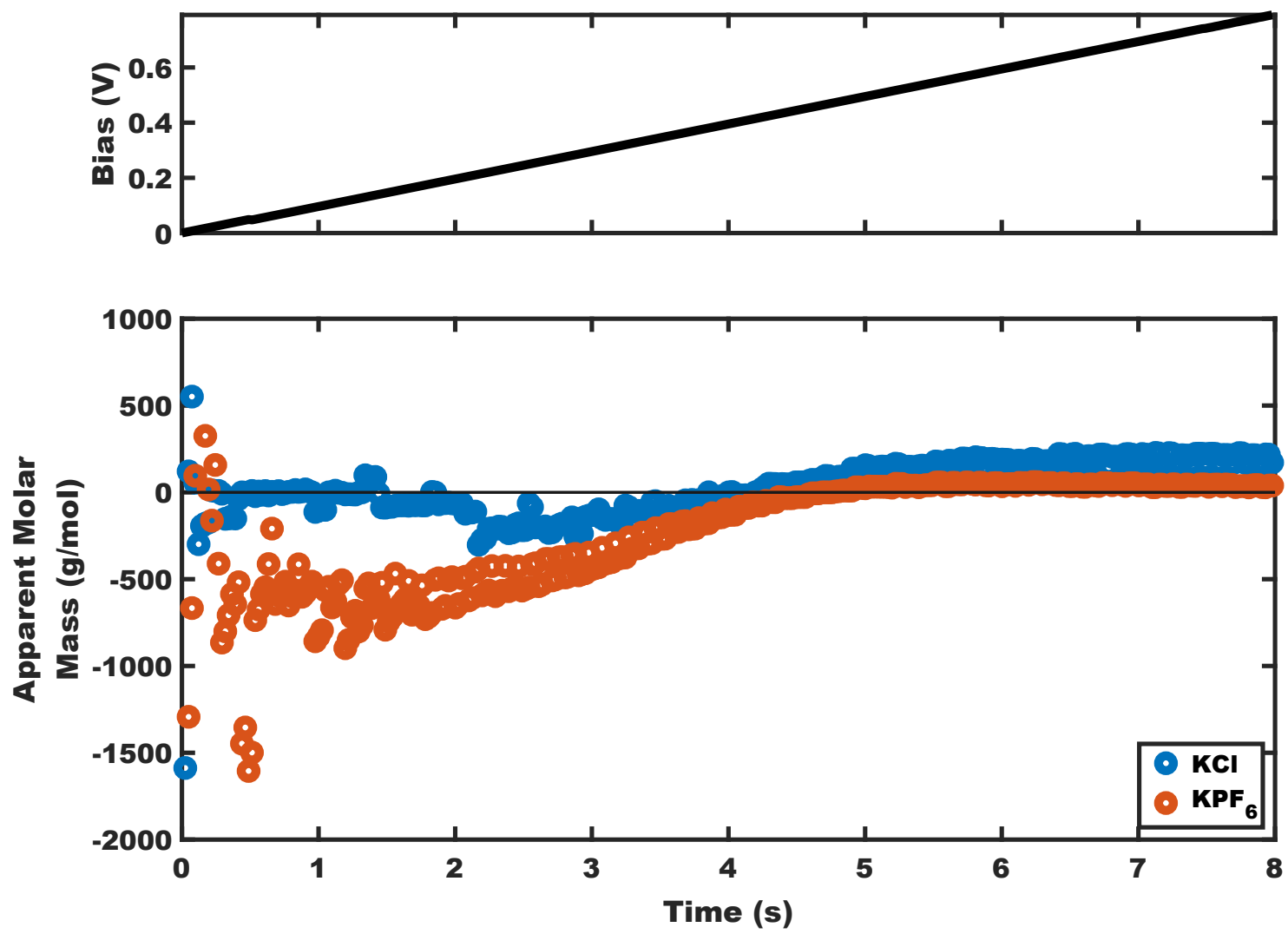

Figure S14: Molar mass per injected charge. At the low doping levels, the magnitude of the apparent molar mass of the dopant species is significantly greater in $\mathrm{KPF}_{6}$ (orange) than in $\mathrm{KCl}$ (blue) implying that there is more solvent expulsion occurring in the $\mathrm{KPF}_{6}$ electrolyte. 


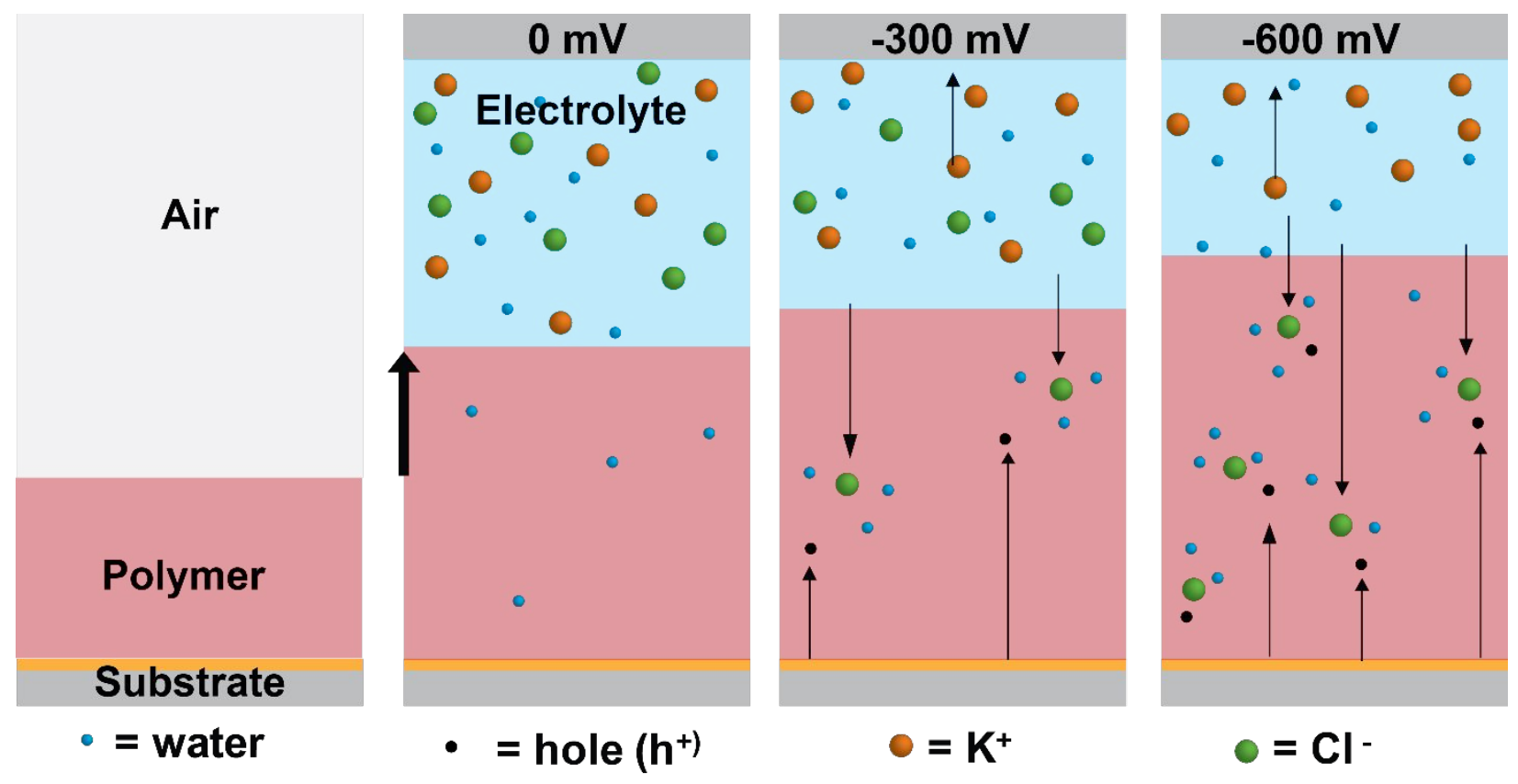

Figure S15: Schematic of doping in $\mathrm{KCl}$. In $\mathrm{KCl}$ we believe there is very little cation/anion content in the film prior to bias. Therefore, all levels of oxidation result in anion injection into the film. 


\section{References:}

(1) Lee, E.; Hammer, B.; Kim, J.-K.; Page, Z.; Emrick, T.; Haywar, R. C. Hierarchical Helical Assembly of Conjugated Poly(3-Hexylthiophene)- Block-Poly(3-Triethylene Glycol Thiophene) Diblock Copolymers. J. Am. Chem. Soc. 2011, 133, 10390-10393.

(2) Zhang, L.; Andrew, T. L. Deposition Dependent Ion Transport in Doped Conjugated Polymer Films: Insights for Creating High-Performance Electrochemical Devices. Adv. Mater. Interfaces 2017, 4, 1700873.

(3) Hillman, A.; Daisley, S. J. S.; Bruckenstein, S.; Robert Hillman, A.; Daisley, S. J. S.; Bruckenstein, S. Solvent Effects on the Electrochemical P-Doping of PEDOT. Phys. Chem. Chem. Phys. 2007, 9, 2379-2388.

(4) Hillman, A. R.; Daisley, S. J.; Bruckenstein, S. Kinetics and Mechanism of the Electrochemical P-Doping of PEDOT. Electrochem. commun. 2007, 9, 1316-1322.

(5) Hillman, A. R.; Daisley, S. J.; Bruckenstein, S. Ion and Solvent Transfers and Trapping Phenomena during N-Doping of PEDOT Films. Electrochim. Acta 2008, 53, 3763-3771.

(6) Gabrielli, C. Calibration of the Electrochemical Quartz Crystal Microbalance. J. Electrochem. Soc. 1991, 138, 2657.

(7) Flagg, L. Q.; Bischak, C. G.; Onorato, J. W.; Rashid, R. B.; Luscombe, C. K.; Ginger, D. S. Polymer Crystallinity Controls Water Uptake in Glycol Side-Chain Polymer Organic Electrochemical Transistors. J. Am. Chem. Soc. 2019, 141, 4345-4354. 